\title{
Solid-Phase Microextraction (SPME) followed by On-Fiber Derivatization of Solasodine and Solanidine Aglycones of Steroidal Glycoalkaloids
}

\section{Ritchie C. Eanes \& Neslihan Tek}

To cite this article: Ritchie C. Eanes \& Neslihan Tek (2008) Solid\#Phase Microextraction (SPME) followed by On\#Fiber Derivatization of Solasodine and Solanidine Aglycones of Steroidal Glycoalkaloids, Journal of Liquid Chromatography \& Related Technologies, 31:8, 1132-1146, DOI: $10.1080 / 10826070802000632$

To link to this article: http://dx.doi.org/10.1080/10826070802000632

Published online: 27 Mar 2008.

Submit your article to this journal $\llbracket$

Џ Article views: 49

View related articles $\sqsubset$

Citing articles: 3 View citing articles $\square$ 
Journal of Liquid Chromatography \& Related Technologies ${ }^{\circledR}, 31:$ 1132-1146, 2008

Copyright (C) Taylor \& Francis Group, LLC

ISSN 1082-6076 print/1520-572X online

DOI: $10.1080 / 10826070802000632$

\title{
Solid-Phase Microextraction (SPME) followed by On-Fiber Derivatization of Solasodine and Solanidine Aglycones of Steroidal Glycoalkaloids
}

\author{
Ritchie C. Eanes and Neslihan Tek \\ Science Faculty, Chemistry Department, Izmir Institute of Technology, \\ Urla, Izmir, Turkey
}

\begin{abstract}
Solid-phase microextraction (SPME), followed by on-fiber derivatization was investigated for the analysis of the steroidal glycoalkaloid aglycones, solasodine and solanidine. The aglycones were first extracted by direct immersion of the SPME fiber in the sample medium and then derivatized on the fiber in a separate step using 1-(trimethylsilyl)imidazole (TMSI). The derivatized compounds were then desorbed from the SPME fiber and detected by GC-MS. Polydimethylsiloxane/Divinylbenzene (PDMS-DVB), Carboxen/Polydimethylsiloxane (CAR-PDMS), and Carbowax/Divinylbenzene (CW-DVB) fibers were employed with the CW-DVB fibers being the most successful, as expected. Closed-end capillary tubes were used to hold the extraction media. Both aglycones were successfully extracted, derivatized, and detected by GC-MS. Solasodine always required derivatization, but solanidine did not.

The same method was successfully applied to cholesterol so that it could be used as an internal standard. Also, using the closed-end capillary tubes, a two-phase extraction system was also investigated, whereby the fiber was only exposed to the phase in which it was presumed to be less damaged. However, in all cases, fiber degradation was significant, preventing the use of extended extraction times and limiting reuse of the fibers. However, the results represent a first look into the feasibility of the method. With the development of more suitable SPME phases, this method could potentially provide a complementary route for routine determinations of glycoalkaloids for both research and food quality control.
\end{abstract}

Keywords: SPME, On-fiber derivatization, Eggplant, Potato, Solanidine, Solasodine, Steroidal glycoalkaloids

Correspondence: Ritchie C. Eanes, Science Faculty, Chemistry Department, Izmir Institute of Technology, Urla, Izmir, Turkey 35430. 


\section{INTRODUCTION}

Steroidal glycoalkaloids (SGAs), as well as their aglycones (SGAAs), have attracted attention, ${ }^{[1-3]}$ not only with regard to their toxicity, ${ }^{[4-8]}$ but also for their potential use in anticancer medicinals. ${ }^{[9-15]}$ Albeit standard liquidliquid extraction methods followed by some type of high performance liquid chromatography (HPLC) detection are widely used for the extraction, separation, and determination of these compounds, ${ }^{[16-28]}$ it is important that efficient complementary methods be developed and employed for control and validation purposes. As a means of convenient sampling and introduction to analytical instrumentation, solid-phase microextraction (SPME) has been extensively investigated for use with gas chromatography $(\mathrm{GC})^{[29-35]}$ and, to a lesser extent, high performance liquid chromatography (HPLC). ${ }^{[29,36,37]}$ Although the fragile structures of SGAs typically preclude their analysis by GC methods, it is, however, possible to determine, by GC, the hydrolyzed aglycone forms of steroidal glycoalkaloids, either directly ${ }^{[38,39]}$ or, when necessary, via derivatization of the aglycones to more volatile forms ${ }^{[39]}$ Furthermore, for studies involving the measurement of glycoalkaloids by traditional methods, researchers, for simplicity, sometimes report their results in terms of a concentration of total glycoalkaloids (TGA) or "equivalents" for a specific aglycone, referring to the combined concentrations of the SGAs under the heading of their respective aglycones, presumably when other SGAs related to that particular aglycone are deemed undetectable (e.g., [solanine SGA] +[chaconine $\mathrm{SGA}]=[$ solanidine $\mathrm{SGAA}])^{[40,41]}$ GC-based analytical methods are commonly coupled with SPME. ${ }^{[29-32,42-45]}$ For this reason, gas chromatography-mass spectrometry (GC-MS) was chosen in the present work as the preferred detection scheme for the investigation of the use of SPME as a complementary means of extraction and sample introduction for the analysis of the SGAAs solasodine and solanidine.

Although solid-phase microextraction (SPME) is traditionally considered applicable mainly to volatile compounds, ${ }^{[45]}$ the feasibility of extracting non-volatile analytes and then performing their derivatization directly on the SPME fiber has become a subject of interest. ${ }^{[4,47]}$ To the best of our knowledge, the technique of SPME followed by "on-fiber derivatization" has not been applied to the extraction of the aglycones of steroidal glycoalkaloids, specifically the two aglycones of interest to our work, solasodine and solanidine. For the work presented here, solasodine and solanidine are first extracted by direct immersion of the SPME fiber in the sample medium and then derivatized on the fiber in a separate step using an appropriate derivatization agent. The derivatized compounds are then desorbed from the SPME fiber into a GC-MS system, where they are separated and detected, thus providing a potential complementary route for routine determinations of glycoalkaloids for both research and food quality control. 


\section{EXPERIMENTAL}

\section{Chemicals, Materials, and Instrumentation}

Standards of solanidine and solasodine were obtained from MP Biochemicals LLC (Ohio, USA) and Research Plus, Inc. (Manasquan, N.J., USA), respectively. Cholesterol (95\% purity) was purchased from Alfa Aesar (Karlsruhe, Germany) to be used as an internal standard. Each of the aglycone stock solutions $(1.0 \mathrm{mg} / \mathrm{mL})$ was prepared in methanol-acetic acid $(95: 5 \mathrm{v} / \mathrm{v})$ unless otherwise stated, and stored at $4^{\circ} \mathrm{C}$. The derivatization agent 1-(trimethylsilyl)imidazole (TMSI) was purchased from Sigma-Aldrich (St. Louis, USA) in $1 \mathrm{~mL}$ ampoules. A manual SPME holder and fibers with different coatings: Polydimethylsiloxane/Divinylbenzene (PDMSDVB, for extraction of polar analytes, $65 \mu \mathrm{m}$ film thickness), Carboxen/Polydimethylsiloxane (CAR-PDMS, for extraction of volatile analytes, $75 \mu \mathrm{m}$ film thickness), and Carbowax/Divinylbenzene (CW-DVB for extraction of polar analytes, especially alcohols, $65 \mu \mathrm{m}$ and $70 \mu \mathrm{m}$ film thickness-Stable Flex) were obtained from Supelco (Bellefonte, PA, USA). Before use, each fiber was conditioned according to the supplier's specifications and a blank analysis was performed to determine the quality of the conditioning.

He gas chromatography-mass spectrometry (GC-MS) system employed for these studies was comprised of a Varian 2000 Ion Trap Mass Spectrometer as interfaced with a Varian Star $3400 \mathrm{C} x$ Gas-Chromatograph (GC) (Walnut Creek, Calfornia USA) that was equipped with a split/splitless programmable temperature injector (SPI/1078, a $3.14 \mathrm{~mm}$ i.d. glass liner), and an SAC-5 type capillary column $(30 \mathrm{mX0} 0.25 \mathrm{~mm}$ i.d., df: $0.25 \mu \mathrm{m})$ purchased from Supelco (Bellefonte, PA, USA). Helium (99.999\%) was used as the carrier gas at a flow rate of $1.0 \mathrm{~mL} / \mathrm{min}$. For experiments that did not employ an SPME step, the GC oven and injector temperatures were kept constant at $275^{\circ} \mathrm{C}$ and $300^{\circ} \mathrm{C}$, respectively. For experiments involving an SPME step, a temperature gradient was applied via the GC oven as follows: $160^{\circ} \mathrm{C}$ held for 3 minutes followed by a temperature gradient ramp of $20^{\circ} \mathrm{C} /$ minute up to $280^{\circ} \mathrm{C}$ which was held for 36 minutes. Using splitless mode, the SPME fibers were desorbed for five minutes in the GC injector. For the PDMS-DVB, CAR-PDMS, and CW-DVB fibers, the GC injector temperatures were $240^{\circ} \mathrm{C}$, $270^{\circ} \mathrm{C}$, and $250^{\circ} \mathrm{C}$, respectively. For all experiments, the GC-MS interface and ion-trap temperatures were fixed at $280^{\circ} \mathrm{C}$ and $200^{\circ} \mathrm{C}$, respectively. The ion trap mass spectrometer was operated in normal electron impact (EI) mode (i.e., $70 \mathrm{eV}$ ) with full scans being aquired from $\mathrm{m} / \mathrm{z} 40$ to $\mathrm{m} / \mathrm{z} 650$.

\section{Derivatization of Aglycones for GC-MS without SPME}

Before the "on-fiber derivatization" scheme unique to this work was evaluated, traditional non-SPME based methods of derivatizating aglycones 
of glycoalkaloids ${ }^{[39]}$ were carried out to gain experience in handling the derivatizing agents and to gain knowledge as a logical first step. Separate aglycone standard solutions, each containing 20 microliters, were placed in 4-mL vials, evaporated to near dryness for 30 minutes, dried at $105^{\circ} \mathrm{C}$ for 5 minutes, and stored in a dessicator with loose caps until they cooled to room temperature. Since TMSI is extremely moisture sensitive, it was handled in an inert argon atmosphere using a specially purchased glove bag (Glove-Bag ${ }^{\mathrm{TM}}, \mathrm{I}^{2} \mathrm{R}$ Glas-Col, Terre Haute, IN). Twenty microliters of TMSI and 50 microliters of dry acetonitrile were added via glass syringe to each vial in the glove bag. Then, the vials were placed in an oven at $60^{\circ} \mathrm{C}$ for 15 minutes for derivatization and then allowed to cool to room temperature. Two microliters of each solution were injected into the GC-MS for analysis.

\section{Direct SPME with On-Fiber Derivatization}

Different methods of applying SPME, both traditional and especially related to the work here, are represented in Fig. 1. In general, SPME involves the adsorptive extraction of an analyte onto a fiber in a closed environment as provided by a vial sealed with a septum-containing cap. For volatile analytes, the extraction step of SPME can be carried out in capped vials as illustrated in Fig. 1a. For compounds with low vapor pressures, such as the glycoalkaloids, a direct immersion method as shown in Fig. $1 \mathrm{~b}$ can be employed. However, as expected, due to the relatively large volume of solution and, hence, the resulting dilution of the glycoalkaloids, this mode of direct immersion was deemed inappropriate for the present work. Instead, for the work presented here, a capillary tube was used to hold the extraction medium, thus decreasing the volume while maintaining a large surface area of contact between solution and fiber. The SPME fiber was then immersed in the solution in the capillary, as shown in Fig. 1c.

Thus, twenty microliters containing both the individual aglycone standard solution (solasodine or solanidine) and the internal standard (cholesterol) were transferred to a 4-cm length and $1 \mathrm{~mm}$ i.d. glass capillary tube which was fixed in a vial (Fig. 1c). The needle of the fiber holder was inserted into the capillary and the fiber was immersed into the solution. In this manner, the microextraction of solanidine was carried out at room temperature for $30 \mathrm{~min}$. Extraction of solasodine proved to be more difficult and, therefore, its extraction time was extended to one hour. After finishing the extraction step, the SPME fiber was exposed to the vapors of TMSI in a 4-mL amber vial (as positioned in an aluminum heating block) at $70^{\circ} \mathrm{C}$ for an hour (Fig. 1e) for derivatization. In a separate set of experiments with polar-based fibers, an extraction step was implemented as represented by Fig. 1d. For these experiments, the analyte as dissolved in a polar methanol-acetic acid medium (solvent B) was allowed to first establish a distribution equilibrium with a hexane upper 


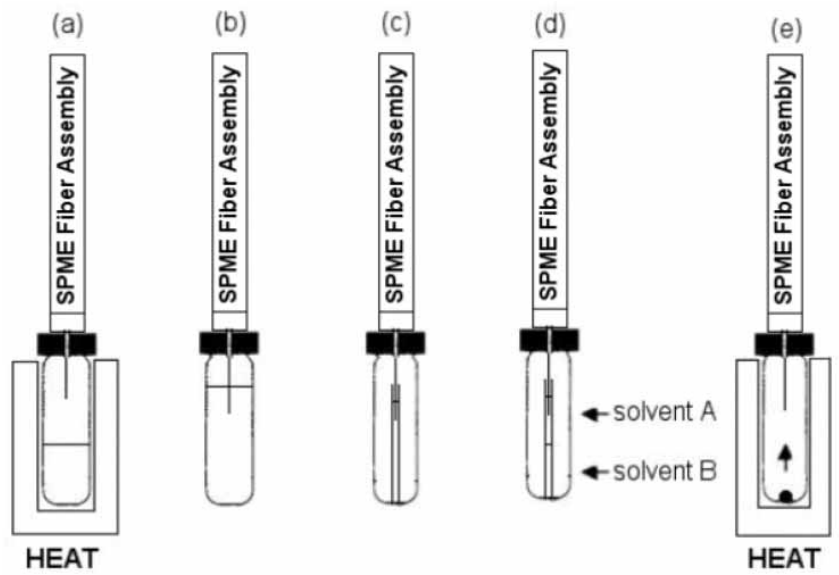

Figure 1. Comparison of modes for extraction and on-fiber derivatization by SPME: (a) traditional headspace extraction, (b) extraction by direct immersion of fiber, (c) extraction by direct immersion of fiber using a capillary tube, (d) liquid-liquid extraction from solvent B to solvent A followed by SPME from solvent A in a capillary tube holding the sample volume, (e) derivatization of extracted analyte which is already adsorbed onto SPME fiber. Note: When heat is applied, vials were housed in an aluminum block as shown.

phase (solvent A) into which the SPME fiber was directly immersed for extraction of glycoalkaloids. This was done to decrease the opportunity for dissolution of the SPME fiber, since it was not in direct contact with the polar extraction solvent. Regardless of extraction method, the SPME fibers were either subsequently sampled directly by GC-MS or were first derivatizated in the manner shown in Fig. 1e prior to sampling by GC-MS.

\section{RESULTS AND DISCUSSION}

For the work with on-fiber SPME, initial experiments were performed using a polar CW-DVB fiber, since solasodine and solanidine are relatively polar compounds. As was the case when "on-fiber derivatization" was not applied (i.e., traditional derivatization without SPME), solasodine always required derivatization prior to GC-MS analysis while solanidine and cholesterol did not. Compared with using vials to hold the sample volume, capillary tubes were preferred because less grams of standard were required per volume of solvent when closed-end capillary tubes were employed. Furthermore, with the capillary setup, only a few microliters of sample was necessary for extraction. Although we truly thought this was a novel direction, further review of the literature revealed that Zhu et al. had already explored this idea recently 
for other SPME analyses unrelated to glycoalkaloids, pointing out in their work that, through the use of capillary tubes, the diffusion distance for analyte to the fiber is reduced, the large amount of fiber compared to liquid favors extraction, only a small amount of sample is required, and they reported that this method reduced the influence of experimental conditions while increasing reproducibility. ${ }^{[48]}$

Thirty minutes was chosen initially for extraction time. After completing the extraction step, the fiber was placed in the headspace of a 4-mL vial which, at the bottom, contained the derivatization reagent, TMSI. Then the vial was heated in a specially made aluminum block at $70^{\circ} \mathrm{C}$ for one hour (Fig. 1e). Under these conditions, two GC-MS peaks were obtained for each compound, corresponding to the derivatized and non-derivatized forms (Fig. 2).

By increasing the amount of TMSI to $40 \mu \mathrm{L}$ and decreasing the concentration of solanidine and cholesterol (to $30 \mathrm{mg} / \mathrm{L}$ for each one), the degree of derivatized product was increased and the underivatized forms were no longer present in the GC-MS spectra (Figs. 3 and 4). Both solanidine and cholesterol produced mono-TMS derivatives ${ }^{[39]}$ with molecular ion peaks at $\mathrm{m} / \mathrm{z} 469$ and $\mathrm{m} / \mathrm{z} 458$ (not shown), respectively.

Unfortunately, using the same protocol, derivatized solasodine was not detected by GC-MS. Extraction and derivatization times were, therefore, increased to 60 minutes. When doing so, it was necessary to heat (condition) each CW-DVB fiber at $250^{\circ} \mathrm{C}$ for 5 minutes in the GC-injector port upon completion of each chromatographic run in order to avoid memory effects and, thus, make it possible to reuse them for subsequent extractions.

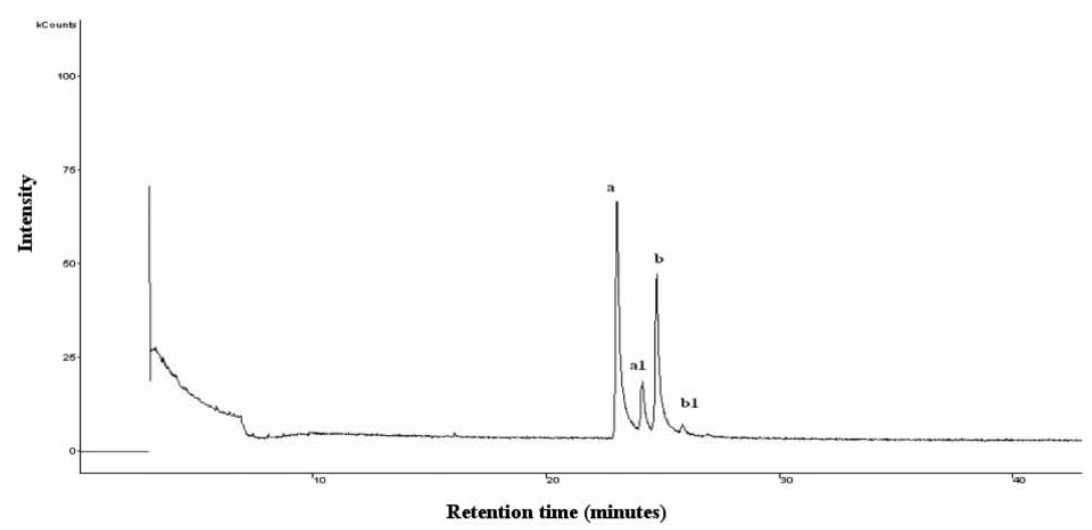

Figure 2. Total ion GC-MS chromatogram of derivatized standard solanidine solution $(300 \mathrm{mg} / \mathrm{L})$ after SPME extraction (CW-DVB fiber); a = underivatized cholesterol (IS); $\mathrm{a}_{1}=$ derivatized cholesterol; $\mathrm{b}=$ underivatized solanidine; $\mathrm{b}_{1}=$ derivatized solanidine. 


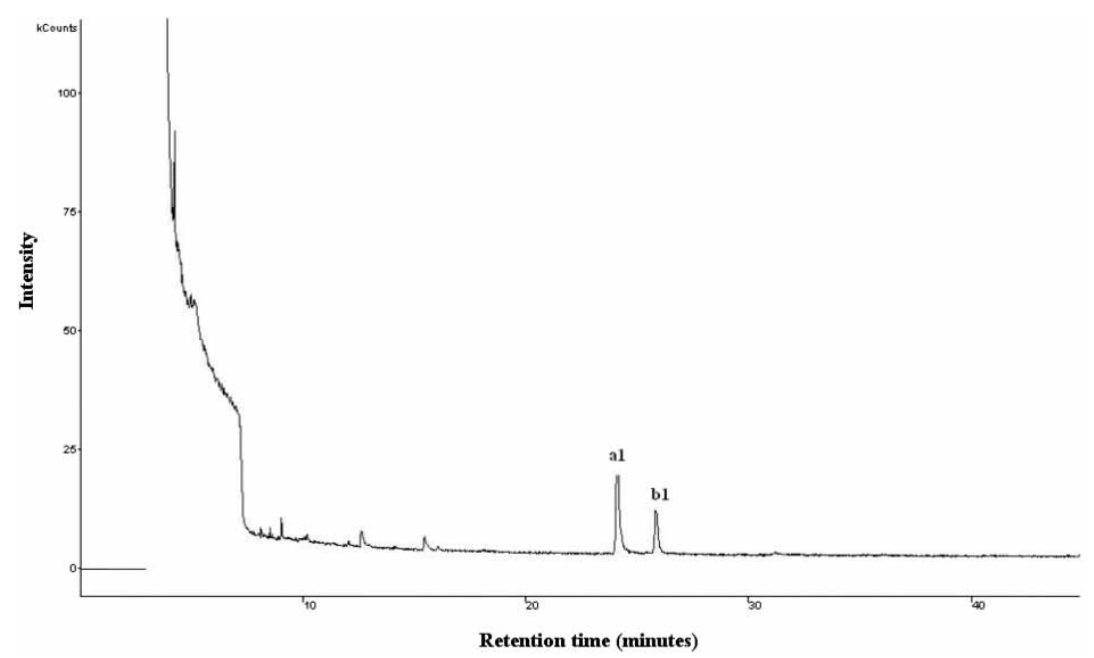

Figure 3. Total ion GC-MS chromatogram of derivatized standard solanidine solution $(30 \mathrm{mg} / \mathrm{L})$ after SPME extraction (CW-DVB fiber); a1 = cholesterol; $\mathrm{b} 1=$ solanidine.

After the first extraction, derivatization, and desorption cycle, no solasodine could be seen. However, only after the same GC-MS analyzed fiber was again exposed for 30 minutes to the vapors from a $40 \mu \mathrm{L}$ fresh aliquot of TMSI (i.e., a second derivatization step without any added extraction step), the derivatized solasodine revealed itself. In its GC-MS spectrum (Fig. 5) and corresponding mass spectrum (Fig. 6), solasodine (from the standard solution) shows the di-TMS derivative ${ }^{[39]}$ after silylation with base peak at $\mathrm{m} / \mathrm{z} 125$ and its proper molecular ion peak cluster. Unfortunately, the centroid data given by our ion trap instrument did not show the di-TMS derivative molecular ion at $\mathrm{m} / \mathrm{z}$ 557. In fact, a quick comparison

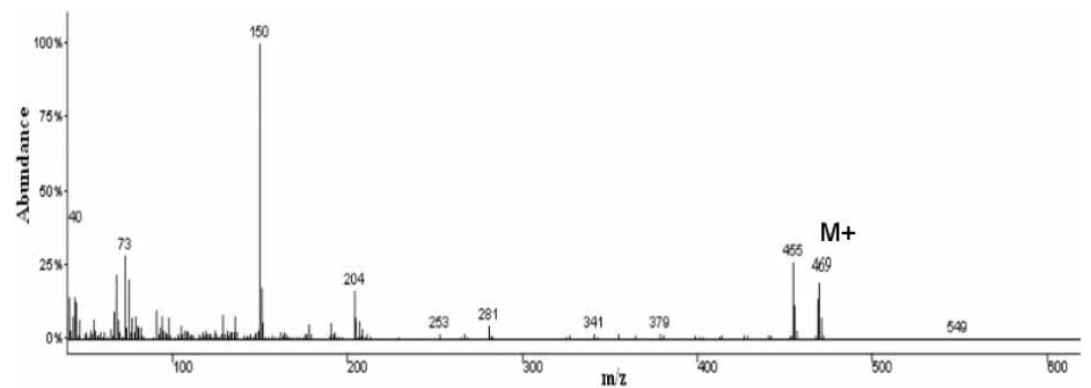

Figure 4. Mass spectrum of derivatized solanidine after SPME extraction and onfiber derivatization. 


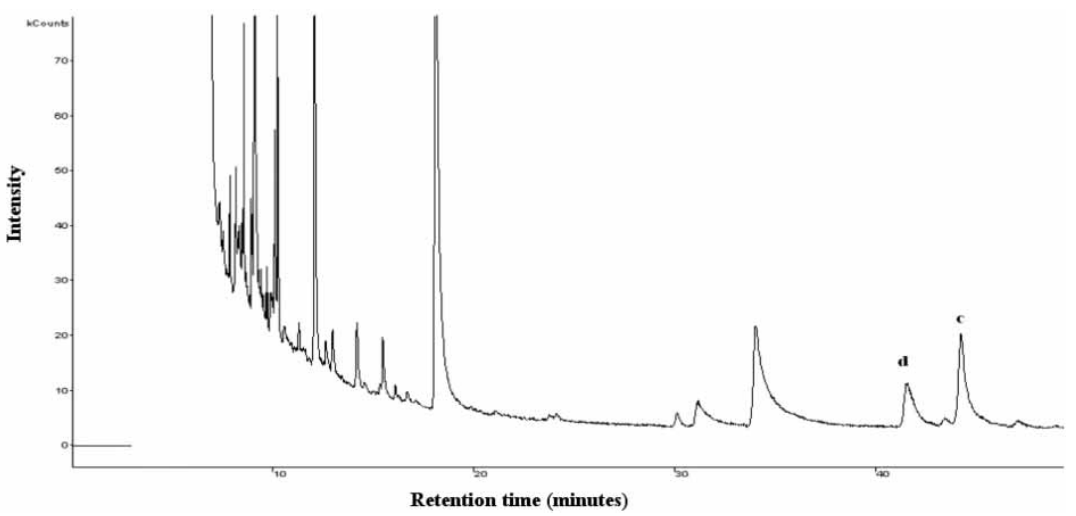

Figure 5. GC-MS chromatogram of derivatized solasodine after SPME extraction of solasodine solution $(300 \mathrm{mg} / \mathrm{L})$ and on-fiber derivatization; peaks 'c' and 'd' both come from derivatized solasodine (CW-DVB fiber).

of the mass spectra of Figs. $6 \mathrm{a}$ and $6 \mathrm{~b}$ shows the primary peak of the molecular ion cluster to be at $\mathrm{m} / \mathrm{z} 559$ and 558, respectively. These mass spectra correspond to the two separate chromatographic peaks shown in Fig. 5. Possibly, the discrepancy was due to either protonation of the molecular ion to give a quasi-molecular ion at 558 (Fig. 6b) but, again, it should be noted that the experiments were run using a carefully prepared solution containing only solasodine standard. Although it would have been preferred that such discrepancies be resolved, they do not diminish the importance of the main topic of this work, namely the development of an SPME and "on-fiber derivatization" method for solasodine and solanidine.

With solasodine having been quite recalcitrant to detection, it was also wondered if the solvent remaining on the fiber after extraction was interfering with the derivatization of solasodine. In a separate experiment, after the extraction step, the fiber was conditioned in the injector port for 5 minutes at $100^{\circ} \mathrm{C}$ in an attempt to remove residual solvent without significantly desorbing the analyte (solasodine). Next, an on-fiber derivatization step was applied for an hour using $40 \mu \mathrm{L}$ TMSI. However, solasodine still could not be seen via GC-MS. Interestingly, when a second derivatization step was performed on the same sample fiber without any other treatment, derivatized solasodine was clearly seen (Fig. 7). Since, for every derivatization step, an excess of TMSI had been used, either residual solvent appears to inhibit efficient derivatization of solasodine while on the fiber or it is possible that removal of the derivatized product from this fiber is particularly difficult. Lending creedence to this idea, the peaks labeled 'c' and 'd' in the chromatogram of Fig. 5 both possessed similar mass spectra in accordance with the structure of derivatized solasodine $(\mathrm{m} / \mathrm{z} 125$ and molecular ion clusters around $\mathrm{m} / \mathrm{z} 558[\mathrm{M}+\mathrm{H}]^{+}$). Very likely, these 


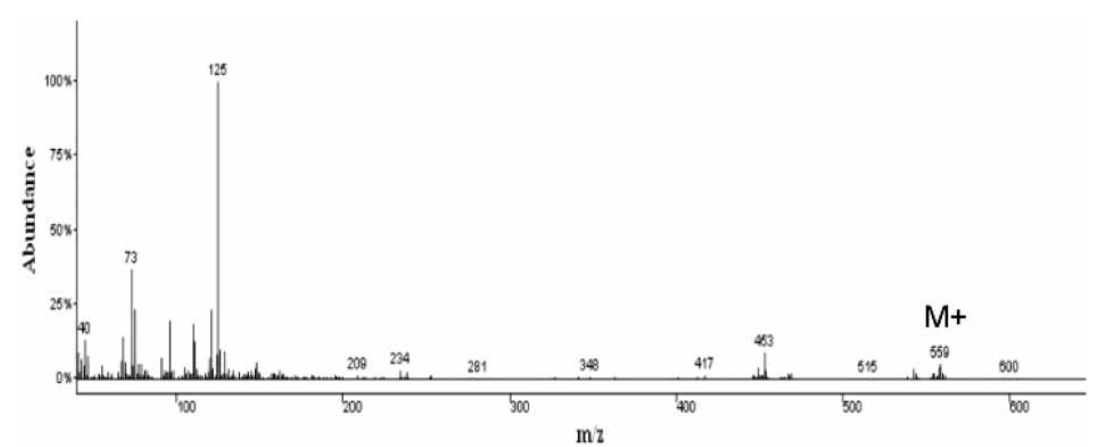

(a)

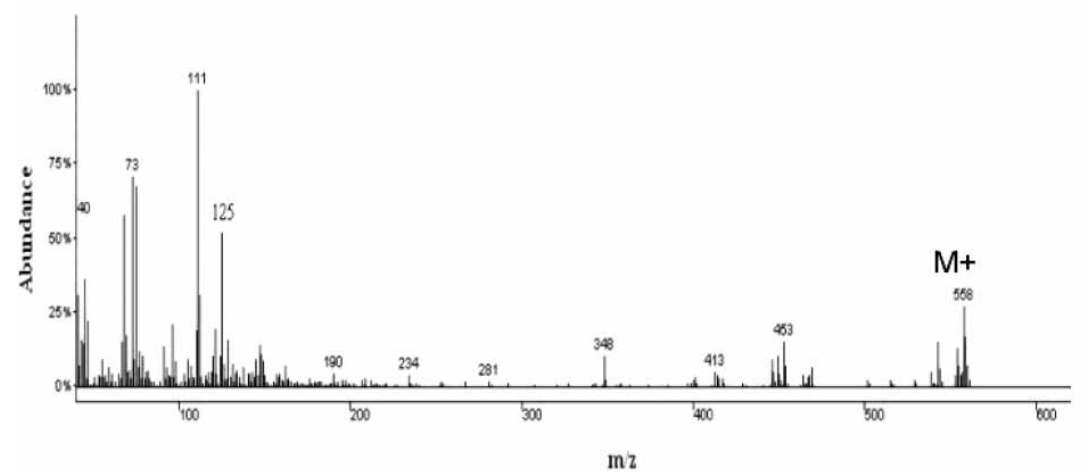

(b)

Figure 6. Mass spectra of (a) peak 'c' and (b) peak 'd' from Fig. 5 (coming from derivatized solasodine).

peaks represent separate desorption events of the solasodine derivative from the SPME fiber.

After several extraction/derivatization cycles using the same CW-DVB fiber, the fiber degraded to an unusable state, as can be witnessed through the gradual increase in background during the first 20 minutes for the chromatograms as represented in Figs. 2, 3, 5, and 7. Most likely, this degradation of the fiber coating was the result of its having been directly immersed in the methanolic solvent for the initial extraction step. In further experiments, PDMS-DVB and CAR-DVB fibers were tried to test their extraction ability for these aglycones, as well as to examine the robustness of these fibers to the extraction medium. Due to their lack of extraction ability for the aglycones, these fibers were immersed into a fresh methanolic solution of solanidine and cholesterol (IS) overnight (an extended period), taken through the derivatization and desorption steps, and finally analyzed by GC-MS. These two compounds were preferentially selected because they had been less problematic than solasodine. The PDMS-DVB fiber extracted only cholesterol. 


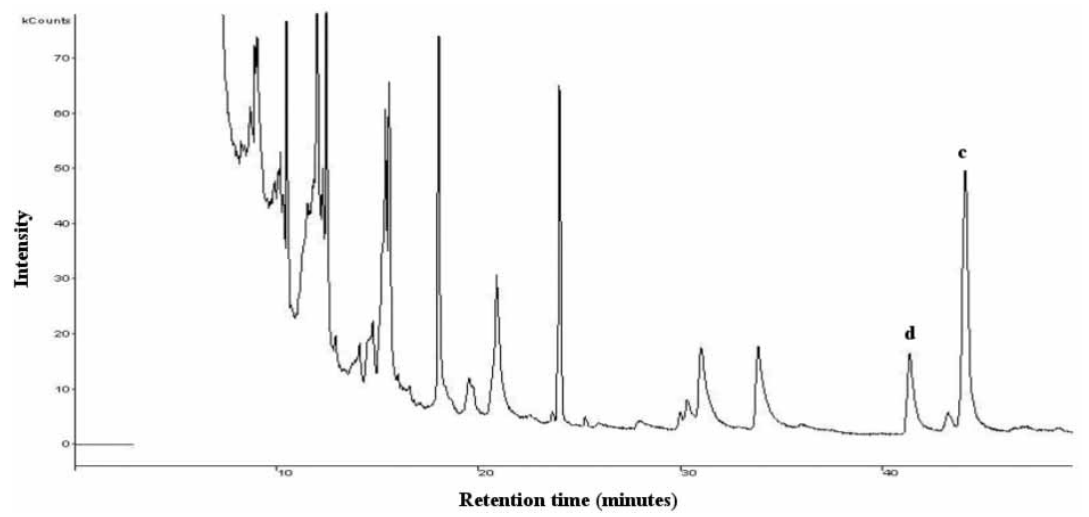

Figure 7. Mass GC-MS chromatogram of derivatized solasodine after SPME extraction of solasodine solution $(300 \mathrm{mg} / \mathrm{L})$ and on-fiber derivatization-(CW-DVB fiber).

However, neither solanidine nor cholesterol were observed in the GC-MS spectra after extraction using the CAR-PDMS fiber. According to the literature, although this fiber is most appropriately applied for SPME of molecules in the $\mathrm{C}_{2}-\mathrm{C}_{12}$ range, analytes with longer carbon chains may be very strongly adsorbed, requiring a high desorption temperature, for example over $300^{\circ} \mathrm{C}^{[45]}$ Shirey and Mindrup, representatives of the manufacturer, also concluded that the CAR-PDMS fibers are best suited for extraction of analytes with molecular masses less than 90 amu. ${ }^{[49]}$ According to product information, the maximum operating temperature of the CAR-PDMS fibers is $320^{\circ} \mathrm{C}^{[50]}$ and is not suitable for polar solvents; ${ }^{[51]}$ therefore, for our experiments, $270^{\circ} \mathrm{C}$ was chosen as a desorption temperature to extend the life of the fiber.

Since using the CW-DVB fiber for extractions had been more successful, attention was again focused on how to use this fiber while reducing its gradual deterioration. To prevent the direct exposure of the polar coating to the methanol-acetic acid (polar) solvent, a secondary extraction was carried out in a non-polar solvent, as illustrated in Fig. 1d. For these studies, the capillary was filled with $20 \mu \mathrm{L}$ solanidine standard solution $(1000 \mathrm{mg} / \mathrm{L})$ in methanol-acetic acid (95:5 v/v) and $20 \mu \mathrm{L}$ hexane was added to the top of the solution (upper phase). A new CW-DVB fiber was immersed for an hour in the hexane phase, thereby preventing its contact with the lower polar phase and then desorbed in the GC injector without a derivatization step. Under these conditions, solanidine was successfully extracted and detected by GC-MS (Fig. 8). The mass spectrum of this underivatized solanidine sample is shown in Fig. 9, with its molecular ion peak at $\mathrm{m} / \mathrm{z}$ 397. Unfortunately, during the replicate extraction (just before derivatization), the fiber coating was completely dissolved from the fiber, rendering it useless. From this work, it can be assessed that using the 


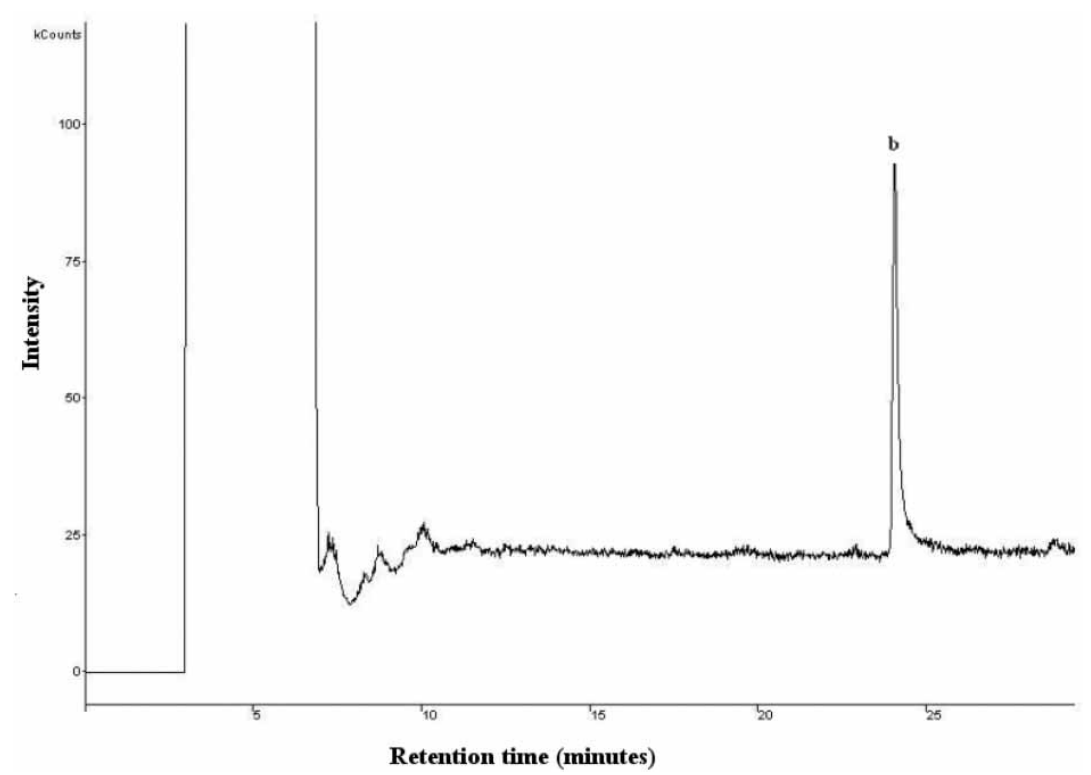

Figure 8. GC-MS chromatogram of underivatized solanidine solution $(1000 \mathrm{mg} / \mathrm{L}$ methanol-acetic acid) after extraction onto a CW-DVB SPME fiber using the method shown in Fig. 1d where solvent $A=$ hexane and solvent $B=$ methanol-acetic acid after SPME extraction; $\mathrm{b}=$ solanidine.

CW-DVB fiber for direct immersion SPME will result in the extraction of solanidine. However, the robustness of the fiber limits its applicability. Perhaps, with the development of more robust stationary phases, direct immersion SPME will be more amenable to extraction of glycoalkaloids and other non-volatile species in the future, but much work remains to be done. In their review of the developments of such materials for use in

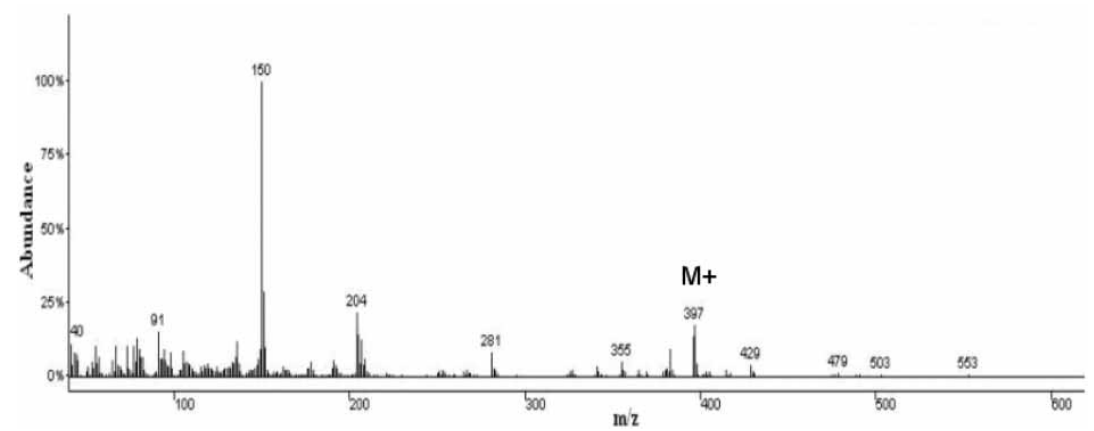

Figure 9. Mass spectrum peak 'b' (underivatized solanidine) in the GC chromatogram of Fig. 8. 
several extraction technologies, Fontanals et al. have included a review of recent works related to the development of sorptive phases for SPME. ${ }^{[52]}$ Likewise, Dietz et al. have reviewed, specifically, the development of coatings for solid-phase microextraction. ${ }^{[53]}$

\section{CONCLUSIONS}

Although the results of this initial testing of the applicability of SPME to the analysis of steroidal glycoalkaloid aglycones were somewhat discouraging, success was achieved and warrants mention. SPME is a useful technique, since it is relatively simple and does not require large amounts of sample solution. Although SPME is normally considered applicable only to volatile species, the method of SPME followed by "on-fiber derivatization" permits the use of this method with GC technologies for the determination of less volatile compounds. The polar CW-DVB phase was suitable for the extraction of solasodine and solanidine. Closed-end capillary tubes were successfully employed here for the extractions. This modification to the traditional use of vials for SPME is considered a practical alternative and has also been demonstrated prior to this work, by Zhu et al. ${ }^{[48]}$ As an extension of this, the use of liquid-liquid extraction and SPME all in one capillary tube is worth further investigation. Finally, studies of solid-phase microextraction followed by "on-fiber derivatization" for the analysis of compounds such as solasodine and solanidine are expected to show significant improvement as researchers continue to develop new sorptive phases for SPME.

\section{ACKNOWLEDGMENTS}

This research was supported by TUBITAK, (Turkey) Project Number TBAG2364 (103T139) and, in part, by Izmir Institute of Technology (IZTECH) Project Number 2004 IYTE 31).

\section{REFERENCES}

1. Chen, Z.; Miller, A.R. Steroidal alkaloids in Solanaceous vegetable crops. Horticult. Rev. 2001, 25, 171-196.

2. Carter, S.J.; Williams, E. Glycoalkaloid compositions and various uses thereof. 2005. United States Patent 25227928.

3. Weissenberg, M. Isolation of solasodine and other steroidal alkaloids and sapogenins by direct hydrolysis-extraction of Solanum plants or glycosides therefrom. Phytochem. 2001, 58, 501-508.

4. Mensinga, T.T.; Sips, A.J.A.M.; Rompelberg, C.J.M.; van Twillert, K.; Meulenbelt, J.; van den Top, H.J.; van Egmond, H.P. Potato glycoalkaloids and 
adverse effects in humans: an ascending dose study. Reg. Tox. Pharm. 2005, 41, $66-72$.

5. Al Chami, L.; Mendez, R.; Chataing, B.; O’Callaghan, J.; Usubillaga, A.; LaCruz, L. Toxicological effects of alpha-solamargine in experimental animals. Phytother. Res. 2003, 17, 254-258.

6. Blankemeyer, J.T.; McWilliams, M.L.; Rayburn, J.R.; Weissenberg, M.; Friedman, M. Developmental toxicology of solamargine and solasonine glycoalkaloids in frog embryos. Food Chem. Tox. 1998, 36, 383-389.

7. Cipollini, M.L.; Levey, D.J. Why are some fruits toxic? Glycoalkaloids in Solanum and fruit choice by vertebrates. Ecology 1997, 78, 782-798.

8. Friedman, M.; Henika, P.R.; Mackey, B.E. Effect of feeding solanidine, solasodine, and tomatidine to non-pregnant and pregnant mice. Food Chem. Tox. 2003, 41, 61-71.

9. Chang, L.-C.; Tsai, T.-R.; Wang, J.-J.; Lin, C.-N.; Kuo, K.-W. The Rhamnose moiety of solamargine plays a crucial role in triggering cell death by apoptosis. Biochem. Biophys. Res. Comm. 1998, 242, 21-25.

10. Kuo, K.-W.; Lin, C.-N. Pharmacological composition for treating cancer cells. United States Patent 6,214,803.

11. Kuo, K.-W.; Hsu, S.-H.; Li, Y.-P.; Lin, W.-L.; Liu, L.-F.; Chang, L.-C.; Lin, C.-C.; Lin, C.-N.; Sheu, H.-M. Anticancer activity evaluation of the Solanum glycoalkaloid solamargine-triggering apoptosis in human hepatoma cells. Biochem. Pharm. 2000, 60, 1865-1873.

12. Liu, L.-F.; Liang, C.-H.; Shiu, L.-Y.; Lin, W.-L.; Lin, C.-C.; Kuo, K.-W. Action of solamargine on human lung cancer cells-enhancement of the susceptibility of cancer cells to TNFs. FEBS Lett. 2004, 577, 67-74.

13. Liang, C.-H.; Liu, L.-F.; Shiu, L.-Y.; Huang, Y.-S.; Chang, L.-C.; Kuo, K.-W. Action of solamargine on TNFs and cisplatin-resistant human lung cancer cells. Biochem. Biophys. Res. Comm. 2004, 322, 751-758.

14. Cham, B.E.; Meares, H.M. Glycoalkaloids from Solanum sodomaeum are effective in the treatment of skin cancers in man. Cancer Lett. 1987, 36, 111-118.

15. Cham, B.E.; Daunter, B. Solasodine glycosides. Selective cytotoxicity for cancer cells and inhibition of cytotoxicity by rhamnose in mice with sarcoma 180 . Cancer Lett. 1990, 55, 221-225.

16. Friedman, M.; Levin, C.E. Reversed-phase high-performance liquid chromatographic separation of potato glycoalkaloids and hydrolysis products on acidic columns. J. Agric. Food Chem. 1992, 40, 2157-2163.

17. Saito, K.; Horie, M.; Hoshino, Y.; Nose, N.; Nakazawa, H. High-performance liquid chromatographic determination of glycoalkaloids in potato products. J. Chromatogr. 1990, 508, 141-147.

18. Dao, L.; Friedman, M. Comparison of glycoalkaloid content of fresh and freezedried potato leaves determined by HPLC and colorimetry. J. Agric. Food Chem. 1996, 44, 2287-2291.

19. Sotelo, A.; Serrano, B. High-performance liquid chromatographic determination of the glycoalkaloids alpha-solanine and alpha-chaconine in 12 commercial varieties of Mexican potato. J. Agric. Food Chem. 2000, 48, 2472-2475

20. Friedman, M.; Roitman, J.N.; Kozukue, N. Glycoalkaloid and calystegine contents of eight potato cultivars. J. Agric. Food Chem. 2003, 51, 2964-2973.

21. Kuronen, P.; Vaananen, T.; Pehu, E. Reversed-phase liquid chromatographic separation and simultaneous profiling of steroidal glycoalkaloids and their aglycones. J. Chromatogr. A. 1999, 863, 25-35. 
22. Stobiecki, M.; Matysiak-Kata, I.; Franski, R.; Skala, J.; Szopa, J. Monitoring changes in anthocyanin and steroid alkaloid glycoside content in lines of transgenic potato plants using liquid chromatography/mass spectrometry. Phytochem. 2003, 62, 959-969.

23. Zywicki, B.; Catchpole, G.; Draper, J.; Fiehn, O. Comparison of rapid liquid chromatography-electrospray ionization tandem mass spectrometry methods for determination of glycoalkaloids in transgenic field-grown potatoes. Anal. Biochem. 2005, 336, 178-186.

24. Dinan, L.; Harmatha, J.; Lafont, R. Chromatographic procedures for the isolation of plant steroids. J. Chromatogr. A. 2001, 935, 105-123.

25. Edwards, E.J.; Cobb, A.H. Improved high-performance liquid chromatographic method for the analysis of potato (Solanum tuberosum) glycoalkaloids. J. Agric. Food Chem. 1996, 44, 2705-2709.

26. Aubert, S.; Daunay, M.C.; Pochard, E. Saponosides steroidiques de l'aubergine (Solanum melonga L.) I. Interet alimentaire, methodologie d'analyse, localisation dans le fruit. Agronomie. 1989, 9, 641-651.

27. Aubert, S.; Daunay, M.C.; Pochard, E. Saponosides steroidiques de l'aubergine (Solanum melonga L.) II. Variations des teneurs liees aux conditions de recolte, aux genotypes et a la quantite de graines des fruits. Agronomie 1989, 9, 751-758.

28. Kodamatani, H.; Saito, K.; Niina, N.; Yamazaki, S.; Tanaka, Y. Simple and sensitive method for determination of glycoalkaloids in potato tubers by high-performance liquid chromatography with chemiluminescence detection. J. Chromatogr. A. 2005, 1100, 26-31.

29. Kataoka, H.; Lord, H.L.; Pawliszyn, J. Review: Applications of solid-phase microextraction in food analysis. J. Chromatgr. A. 2000, 880, 35-63.

30. Kataoka, H.; Terada, Y.; Inoue, R.; Mitani, K. Determination of isophorone in food samples by solid-phase microextraction coupled with gas chromatography-mass spectrometry. Chromatogr. A. 2007, 1155, 100-104.

31. Mills, G.A.; Walker, V. Review: Headspace solid-phase microextraction procedures for gas chromatographic analysis of biological fluids and materials. J. Chromatogr. A. 2000, 902, 267-287.

32. Ouyang, G.; Chen, Y.; Setkova, L.; Pawliszyn, J. Calibration of solid-phase microextraction for quantitative analysis by gas chromatography. J. Chromatogr. A. 2005, 1097, 9-16.

33. Ridgway, K.; Lalljie, S.P.D.; Smith, R.M. Review: Sample preparation techniques for the determination of trace residues and contaminants in foods. J. Chromatogr. A. 2007, 1153, 36-53.

34. Sampedro, M.C.; Martin, O.; Lopez de Armentia, C.; Goicolea, M.A.; Rodriguez, E.; Gomez de Balugera, Z.; Costa-Moreira, J.; Barrio, R.J. Solid-phase microextraction for the determination of systemic and non-volatile pesticides in river water using gas chromatography with nitrogen-phosphorus and electroncapture detection. J. Chromatogr. A. 2000, 893, 347-358.

35. Santos, F.J.; Galceran, M.T. The application of gas chromatography to environmental analysis. Trends Anal. Chem. 2002, 21, 672-684.

36. Lord, H.; Pawliszyn, J. Review: Evolution of solid-phase microextraction technology. J. Chromatogr. A. 2000, 885, 153-193.

37. Lord, H. Review: Strategies for interfacing solid-phase microextraction with liquid chromatography. J. Chromatogr. A. 2007, 1152, 2-13. 
38. Lawson, D.R.; Erb, D.R.; Miller, A.R. Analysis of Solanum alkaloids using internal standardization and capillary gas chromatography. J. Agric. Food Chem. 1992, 40, 2186-2191.

39. Laurila, J.; Laakso, I.; Vaananen, T.; Kuronen, P.; Huopalahti, R.; Pehu, E. Determination of solanidine- and tomatidine-type glycoalkaloid aglycons by gas chromatography/mass spectrometry. J. Agric. Food Chem. 1999, 47, 2738-2742.

40. Kittipongpatana, N.; Porter, J.R.; Hock, R.S. An improved high performance liquid chromatographic method for the quantification of solasodine. Phytochem. Anal. 1999, 10, 26-31.

41. Yencho, G.C.; Kowalski, S.P.; Kobayashi, R.S.; Sinden, S.L.; Bonierbale, M.W.; Deahl, K.L. QTL mapping of foliar glycoalkaloid aglycones in Solanum tuberosum x $S$. berthaultii potato progenies: quantitative variation and plant secondary metabolism. Theor. Appl. Genet. 1998, 97, 563-574.

42. Camarasu, C.; Madichie, C.; Williams, R. Recent progress in the determination of volatile impurities in pharmaceuticals. Trends Anal. Chem. 2006, 25, 768-777.

43. Ouyang, G.; Pawliszyn, J. Recent developments in SPME for on-site analysis and monitoring. Trends Anal. Chem. 2006, 25, 692-703.

44. Snow, N.H.; Slack, G.C. Head-space analysis in modern gas chromatography. Trends Anal. Chem. 2002, 21, 608-617.

45. Pawliszyn, J. Applications of Solid-Phase Microextraction; Royal Society Chemistry: Cambridge, 1999; 520 pp.

46. Carpinteiro, J.; Quintana, J.B.; Rodriguez, I.; Carro, A.M.; Lorenzo, R.A.; Cela, R. Applicability of solid-phase microextraction followed by on-fiber silylation for the determination of estrogens in water samples by gas chromatography-tandem mass spectrometry. J. Chromatogr. A. 2004, 1056, 179-185.

47. Stashenko, E.E.; Martinez, J.R. Derivatization and solid-phase microextraction. Trends Anal. Chem. 2004, 23, 553-561.

48. Zhu, P.-L.; Liu, C.-L.; Liu, M.-C. Solid-phase microextraction from small volumes of sample in a glass capillary. J. Chromatogr. A. 2003, 988, 25-32.

49. Shirey, R.E.; Mindrup, R.F. A Systematic Approach for Selecting the Appropriate SPME Fiber; Sigma-Aldrich: Bellefonte PA, USA, 1999, Supelco Product Information T400156.

50. Supelco. Solid Phase Microextraction Fiber Assemblies; Sigma-Aldrich: Bellefonte PA, USA, 1999, Supelco Data Sheet T794123M.

51. Supelco. Solid Phase Microextraction Troubleshooting Guide Bulletin 928; Sigma-Aldrich: Bellefonte PA, USA, 2001, Supelco Product Information T101928.

52. Fontanals, N.; Marce, R.M.; Borrull, F. New materials in sorptive extraction techniques for polar compounds. J. Chromatogr. A. 2007, 1152, 14-31.

53. Dietz, C.; Sanz, J.; Camara, C. Recent developments in solid-phase microextraction coatings and related techniques. J. Chromatogr. A. 2006, 1103, 183-192.

Received September 30, 2007

Accepted November 19, 2007

Manuscript 6225 